\title{
Periton Diyalizi Hastalarında Yeni Bir Endotel Fonksiyonu Belirteci: Apelin
}

\section{A New Marker For Endothelial Function in Peritoneal Dialysis Patients: Apelin}

\author{
Serhat Karadağ, Meltem Gürsu*, Savaş Öztürk*, Ahmet Gürdal**, Filiz Basınoğlu***, \\ Zeki Aydın*, Sami Uzun*, Abdullah Şumnu*, Eray Atalay, Hüseyin Oflaz**, Rümeyza Kazancıoğlu**** \\ Kafkas Üniversitesi Tıp Fakültesi, Iç Hastalıkları Anabilim Dalı, Kars, Türkiye \\ *Haseki Eğitim ve Araştırma Hastanesi, Nefroloji Kliniği, Istanbul, Türkiye \\ **istanbul Üniversitesi İstanbul Tıp Fakültesi, Kardiyoloji Anabilim Dalı, İstanbul, Türkiye \\ ***Haseki Eğitim ve Araştırma Hastanesi, Biyokimya Kliniği, istanbul, Türkiye \\ ****Bezm-i Alem Vakıf Üniversitesi Tıp Fakültesi, iç Hastalıkları Anabilim Dalı, Nefroloji Bilim Dalı, istanbul, Türkiye
}

\section{Özet}

Amaç: Son dönem böbrek yetersizliğinde en önemli mortalite sebebi kardiyovasküler hastalıklardır (KVH). KVH patogenezinde en önemli basamaklardan birisi endotel disfonksiyonudur (ED). Apelin son yıllarda kardiyovasküler sistem ve endotel fizyolojisinde önemli rolleri gösterilmiş bir peptiddir. Çalışmamızda periton diyalizi (PD) hastalarında apelin ile endotel fonksiyonları arasındaki ilişkiyi incelemeyi planladık.

Yöntem: Haseki Eğitim ve Araştırma Hastanesi PD Ünitesi'nden takipli 42 hasta çalışmaya alındı. Endotel fonksiyonları ultrasonografik olarak akım aracılı dilatasyon (AAD) yüzdesi ile değerlendirildi. Hastalarda alınan kan örneklerinde rutin biyokimyasal tetkikler ve apelin ölçümü yapıldı.

Bulgular: Apelin ile AAD yüzdesi arasında negatif korelasyon saptandı $(r=-0.334, p=0.03)$. AAD yüzdesi ile trigliserid ve çok düşük dansiteli lipoprotein (VLDL) düzeyleri arasında pozitif korelasyon olduğu görüldü (sırasıyla r=0.310, p=0.046; $r=0.304, p=0.05$ ). AAD yüzdesi ile sistolik kan basınc ve diyastolik kan basıncı arasında anlamlı negatif korelasyon mevcuttu (sırasıyla $r=0.565, p=<0.001$; $r=0.560, p=<0.001)$. Hipertansiyon olan grupta olmayan gruba göre $A A D$ yüzdesi belirgin olarak düşük bulundu (sırasıyla $9.0 \pm 5.8$ ve 14.9 $\pm 6.6 ; p=0.01$ ).

Sonuç: ED PD hastalarında hipertansiyon ve lipid profili ile yakın ilişkilidir. Apelin ise PD hastalarında $E D$ açısından yeni bir belirteç ve tedavi alternatifi olarak kullanılabilir. (Haseki Tıp Bülteni 2013; 51: 5-10) Anahtar Kelimeler: Apelin, endotel disfonksiyonu, periton diyalizi
Aim: The most important cause of death in end-stage renal disease is cardiovascular diseases (CVDs). Endothelial dysfunction (ED) is one of the most important steps in the pathogenesis of CVD. Apelin is a peptide recently found to have important roles in cardiovascular and endothelial physiology; and we planned in our study to examine the relationship between apelin and endothelial functions in peritoneal dialysis (PD) patients.

Methods: Forty-two patients who were followed up in the PD unit at Haseki Training and Research Hospital were involved. Endothelial functions were evaluated ultrasonographically by flow-mediated dilation (FMD) test. Apelin levels and routine laboratory tests were studied from the blood samples obtained from the patients.

Results: There was a negative correlation between apelin and FMD percentage $(r=-0.334, p=0.03)$. FMD percentage positively correlated with triglyceride and very low density lipoprotein levels $(r=0.310, p=0.046 ; r=0.304, p=0.05$, respectively). FMD percentage significantly positively correlated with systolic and diastolic blood pressure $(r=0.565, p=<0.001 ; r=0.560, p=<0.001$, respectively). FMD was significantly lower patients with hypertension, compared to those without hypertension ( $9 \pm 5.8$ vs. $14.9 \pm 6.6 ; p=0.01$ ).

Conclusion: ED is closely related with hypertension and lipid profile in PD patients. Apelin may be used as a new marker for ED and a treatment alternative in PD patients. (The Medical Bulletin of Haseki 2013; 51: 5-10)

Key Words: Apelin, endothelial dysfunction, peritoneal dialysis

\section{Giriş}

Son dönem böbrek yetersizliğinde (SDBY) mortalite normal popülasyona göre daha fazladır ve bunun en önemli nedeni kardiyovasküler hastalıklardır (KVH). Diyaliz hastalarında tüm ölüm nedenlerinin yaklaşı \%40-60'ından $\mathrm{KVH}$ sorumludur (1). Kronik böbrek hastalığında $(\mathrm{KBH})$, özellikle SDBY'de geleneksel risk faktörlerine (diabetes 
mellitus, hipertansiyon gibi) ek olarak üremik ortama özgün risk faktörlerinin eklenmesi ile $\mathrm{KVH}$ riski ve ağırlığı artış gösterir (1). Üremik hastalarda da KVH'nın ilk adımının endotel disfonksiyonu (ED) olduğu ve bu olayın renal fonksiyon kaybı ile paralel olarak artıı̆ı kabul edilir (2).

Apelin, son yıllarda patofizyolojik etkileri tanımlanmaya başlayan peptid yapıda bir moleküldür ve APJ isimli reseptörü üzerinden etki yapar $(3,4)$. Yüksek homoloji gösteren APJ reseptörü ile anjiyotensin 2 tip 1 reseptörünün doku ekspresyonları benzerlik gösterir (5). APJ reseptörü; küçük intramiyokardiyal, renal, pulmoner ve akciğer damarlarının endotel hücrelerinde, koroner arterlerde, endokardiyal hücrelerde ve vasküler düz kas hücrelerinde saptanmıştır (6). Insanlarda pre-proapelin santral sinir sistemi, plasenta, böbrek, kalp, akciğer ve meme bezleri başta olmak üzere vücutta yaygın olarak bulunur (7).

Apelin normalde endotel hücrelerinde epitelyal nitrik oksit (NO) sentaz ile NO sentezini arttırarak cGMP düzeyini arttıır ve vazodilatasyon yapar; böylece kan basıncını düşürür (8). Ancak disfonksiyone endotel varlığında vazokonstrüksiyon yapar (9). Kardiyak pozitif inotropik (10) ve antidiüretik hormon salınımını inhibe edici etkisi (11) de olduğu bilinen apelinin hemodiyaliz hastalarında üremik kardiyomiyopati (12) ve ED fizyopatolojisinde rolü olabileceği ileri sürülmüştür (13). Apelinin endotel fonksiyonları üzerine etkisi üremik hastalarda, özellikle de periton diyalizi (PD) hastalarında tam olarak açıklanamamıştır. Bu çalışmanın amacı PD hastalarında apelin ile endotel fonksiyonları arasındaki ilişkiyi incelemektir.

\section{Gereç ve Yöntem}

Çalışmamız kesitsel bir çalışma olarak planlandı ve Haseki Eğitim ve Araştırma Hastanesi PD Ünitesi'nden takipli kronik PD hastaları ile yapıldı. Çalışma için 3 aydan kısa süreyle PD yapılan hastalar, 18 yaş altı ve 80 yaş üstü hastalar, aşikar kalp kapak hastalı̆ıı, atriyal fibrilasyon gibi disritmileri olan hastalar, aktif sistemik enfeksiyonu olan hastalar, malignitesi olan hastalar, son bir ay içinde peritonit geçiren hastalar, klinik olarak aşikar hipervolemisi olan hastalar ve New York Kalp Cemiyeti sınıf 3 ve 4 kalp yetersizliği olan hastalar dışlandı.

Toplam 42 hastanın dahil edildiği bu çalışmada hastaların yaş, cinsiyet, boy, kilo ve vücut kitle indeksi gibi demografik verilerinin yanında primer böbrek hastalıkları, KBY ve PD süreleri ve kullandığı ilaçlar kaydedildi. Tüm hastaların rutin hematolojik ve biyokimyasal tetkikleri için 12 saatlik açlık sonrasında kanları alındı.

Laboratuvar Yöntemleri: Gece 8-12 saatlik açıktan sonra alınan kan örnekleri $-80^{\circ} \mathrm{C}$ derecede saklandı. Apelin düzeyleri Phoenix Pharmaceuticals, Inc marka, Human Apelin-36 Enzyme Immunoassay Kiti ile yarışmalı enzim immünassay metodu kullanılarak çalışıldı.
Ayrıca kan örneklerinden serum glukoz, ürik asit, üre, kreatinin, kolesterol, trigliserid, sodyum, potasyum, fosfor, kalsiyum, parathormon (PTH), total protein, albümin, alanin transaminaz (ALT), aspartat transaminaz (AST), lökosit, hemoglobin, hematokrit, ferritin ve "high sensitive" (yüksek duyarlılklı) C-reaktif protein (hsCRP) düzeyleri belirlendi. Serum ürik asit, glukoz, üre, kreatinin, kolesterol, trigliserid, total protein, albümin, AST, ALT, sodyum, potasyum, serum seviyeleri Siemens Advia 2400 otoanalizörü kullanılarak rutin laboratuar metotlarıla üretici talimatlarına göre yapıldı. Hematolojik parametreler için ABX Pentra DX120 cihazı kullanıldı. Intakt PTH ve ferritin düzeyleri Siemens Advia Centaur ${ }^{\circledR} \quad X P$ cihazı ile immunoassay yöntemi ile değerlendirildi. hsCRP düzeyleri Advia 2400® cihazı ile turbidometrik yöntemle ölçüldü.

Kan Basıncı Ölçümü: Kan basıncı, muayene odasında hastalara en az 10 dakikalık istirahat süresi sonrası sakin bir ortamda kol kalp hizasında ve desteklenerek oskültatuar metot ile her 2 koldan ölçüldü ve yüksek olan değer esas alındı. Korotkoff faz 1 sistolik kan basıncı, faz 5 diyastolik kan basıncı olarak değerlendirildi.

Periton Esitleme Testi (PET): Baxter Healthcare Corporation RenalSoft ${ }^{\mathrm{TM}}$ version 2.0.1 programı kullanılarak standart PET testi yapıldı.

Endotel Fonksiyonu Değerlendirilmesi: Brakiyal arterin akım aracılı dilatasyonu (AAD) brakiyal arterin ultrasonografik incelenmesi ile gerçekleştirildi ve $10 \mathrm{MHz}$ lineer transdüser bağlı standart Vingmed System Five, Horten, Norway cihazı kullanıldı. Hastaların inceleme öncesi egzersiz yapmamaları sağlandı ve işlem 21-23 ${ }^{\circ} \mathrm{C}$ sıcaklıkta 8-12 saat açlık döneminden sonra yapıldı. Hastaların son 12 saat içinde alkollü ve kafeinli içecek almamaları sağlanarak 10 dakikalık istirahat sonrası kan basınçları ölçüldü. Hastalar sırtüstü pozisyona alınarak dominant kolun brakiyal arteri antakubital fossanın üzerinde bulunarak transdüser üzerine kondu ve iki boyutlu longitudinal B-mod görüntüleri alındı. Brakiyal arter iç çapı diyastol sonunda üç kardiyak siklusta (QRS kompleksleri takibiyle) ölçüldü ve ortalamaları bazal değer olarak alındı. Daha sonra ön kolda iskemi oluşturmak için tansiyon aletinin manşonu 200 mmHg üzerine çıkarılarak beş dakika bu pozisyonda tutuldu. Sonrasında manşon indirildikten 60 saniye sonrasında brakiyal arter iç çapı ölçümleri tekrarlandı. AAD yüzdesi bazal değere göre meydana gelen artış olarak ifade edildi. AAD yüzdesi için [(manşon indirildikten sonra ölçülen arter çapı-bazal arter çapı)/bazal arter çapı) x 100] formülü kullanıldı.

Veri Analizi: îstatistiksel analizler SPSS (Statistical Package for Social Sciences) sürüm 14.0 paket programı kullanılarak yapıldı. Sayısal (nümerik) veriler ortalama \pm standart sapma (SD) olarak verildi. iki grup karşılaştırmasında eşleştirilmiş student ttesti veya gerektiğinde Mann-Whitney U testi kullanıldı. Sayısal 


\begin{tabular}{|c|c|c|c|}
\hline & Ort „st. sp. & Minimum & Maksimum \\
\hline Yaş (yll) & $50.7 \pm 16.1$ & 24 & 75 \\
\hline Cinsiyet (K/E) & $22 / 20$ & & \\
\hline Boy $(\mathrm{cm})$ & $162 \pm 10.6$ & 143 & 187 \\
\hline Kilo (kg) & $70.7 \pm 16.6$ & 44 & 105 \\
\hline VYA $\left(\mathrm{kg} / \mathrm{m}^{2}\right)$ & $1.74 \pm 0.22$ & 1.37 & 2.24 \\
\hline VKi $\left(m^{2}\right)$ & $27.1 \pm 6.2$ & 15.9 & 41.3 \\
\hline KBH süre (yll) & $7.6 \pm 5$ & 1 & 26 \\
\hline Sistolik KB (mmHg) & $127.6 \pm 21.9$ & 90 & 180 \\
\hline Diyastolik KB (mmHg) & $79.8 \pm 11.8$ & 60 & 100 \\
\hline Ortalama KB (mmHg) & $95.7 \pm 14.7$ & 70 & 126 \\
\hline PD süresi (ay) & $44.1 \pm 23.4$ & 6 & 96 \\
\hline \multirow{6}{*}{ Primer Böbrek Hastalıkları n (\%) } & Hipertansiyon & $6(14)$ & \\
\hline & Bilinmeyen & $11(26)$ & \\
\hline & Diabetes mellitus & $11(26)$ & \\
\hline & Glomerülonefrit & $4(10)$ & \\
\hline & ODPKBH & $3(7)$ & \\
\hline & Postrenal nedenler & $7(17)$ & \\
\hline \multirow[t]{5}{*}{ Yandaş hastallklar n (\%) } & HT & 30 (71) & \\
\hline & DM & $15(36)$ & \\
\hline & Hiperlipidemi & $15(36)$ & \\
\hline & İskemik kalp hastalığı & $6(14)$ & \\
\hline & Kalp yetersizliği & $2(5)$ & \\
\hline
\end{tabular}

olmayan veriler için uygun olması durumunda $2 \times 2$ olasılık tabloları için Yates düzeltmeli ki-kare testi ve Fisher'in kesinlik (Fisher's exact) testi kullanıldı. Sayısal parametreler arasındaki korelasyonların analizi Pearson, sayısal olmayanlar arasındaki korelasyonlar ise Spearman'in ro(rho) korelasyon testi ile yapıldı. Tüm analizler \%95 güven aralığında yapıldı, $p<0.05$ düzeyi istatistiksel olarak anlamlı kabul edildi

\section{Bulgular}

Çalışmaya, PD tedavisi görmekte olan 69 hasta arasından, çalışmaya katılmayı kabul eden ve çalışmaya alınma kriterlerini karşılayan toplam 42 hasta alındı. Tüm hastaların demografik verileri, primer böbrek hastalıkları ve yandaş hastalıkları Tablo 1'de, biyokimyasal ve hematolojik analiz sonuçları ise Tablo 2'de verilmiștir.

Hastalarda ortalama apelin düzeyi $1.46 \pm 0.41 \mathrm{ng} / \mathrm{ml}$ (minmaks: $0.724-2.724 \mathrm{ng} / \mathrm{ml}$ ) bulundu. Ortalama AAD yüzdesi 10.7 \pm 6.5 (min-maks: 1.6-28) saptandı.

Apelin düzeyleri cinsiyetler arasında anlamlı bir fark göstermedi (kadınlarda $1.51 \mathrm{ng} / \mathrm{ml}$, erkeklerde $1.37 \mathrm{ng} / \mathrm{ml}$; $p=0.141)$. AAD yüzdesi ile apelin düzeyleri arasında negatif bir korelasyon ( $r=-0.334, p=0.03$ ) bulundu.

$A A D$ yüzdesi ile biyokimyasal ve hemogram parametreleri ile yapılan korelasyon analizlerinde sadece trigliserid ve çok düşük dansiteli lipoprotein (VLDL) düzeyleri ile pozitif bir korelasyon gözlendi (sırasıyla $r=0.310, p=0.046 ; r=0.304, p=0.05$ ). Hastalardan elde edilen PET sonuçları Tablo 3'te gösterilmiştir. $A A D$ yüzdesi ile herhangi bir $P D$ yeterlilik parametresi arasında ilişki yoktu. AAD yüzdesi ile sistolik kan basıncı (SKB) ve diyastolik kan basıncı (DKB) arasında anlamlı negatif korelasyon mevcuttu (sirasiyla $r=0.565, p=<0.001$ ve $r=0.560, p=<0.001$ ).

$A A D$ yüzdesi $H T$ 'si olan $P D$ hastalarımızda olmayanlara göre belirgin şekilde daha düşüktü (sırasıyla $\% 9.0 \pm 5.8$ ve $\% 14.9 \pm 6.6 ; p=0.012$ ). AAD yüzdesi hiperlipidemisi olan grup ile olmayan grup arasında anlamlı bir fark göstermedi (sırasıyla $\% 9.8 \pm 6.3$ ve $\% 12.2 \pm 6.8 ; p=0.254)$. AAD yüzdesi diyabetik olmayanlarda diyabetiklere göre daha yüksekti (sırasıyla $\% 11.7 \pm 7$ ve $\% 7.7 \pm 4 ; p=0.028$ ). AAD yüzdesi iskemik kalp hastalığı (IKH) olan ve olmayan grup arasında istatiksel açıdan bir fark göstermedi (sırasılla \%12 \pm 7.0 ve $\% 10.5 \pm 6.5$; $p=0.565)$. Kalp yetersizliği $(K Y)$ olan grupta $A A D$ yüzdesi belirgin olarak düşüktü, ancak istatiksel açıdan anlamlı bir fark göstermedi (sırasılya \%5.6 \pm 5.6 ve $\% 10.9 \pm 6.5 ; p=0.215$ ).

AAD yüzdesi, rezidüel renal fonksiyonu olan hasta grubuyla olmayan grup arasında anlamlı bir fark göstermemekteydi (sırasiyla \%11.3 \pm 6.9 ve $\% 9.9 \pm 6.1 ; p=0.519$ ).

Anjiyotensin dönüştürücü enzim inhibitörü (ACE-i) veya anjiyotensin reseptör blokerleri (ARB) kullanan hastalar ( $n=11)$ 
bir gruba alınıp AAD yüzdesi bakıldığında (\%7.2 44.8$)$, AAD

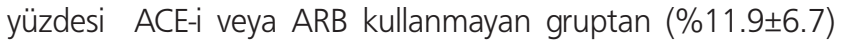
anlamlı olarak düşüktü $(p=0.05)$. Statin kullanan hastalarda, kullanmayan hastalara göre $A A D$ yüzdesi benzer bulundu

\begin{tabular}{|c|c|c|c|}
\hline & Ort $\pm S D$ & Minimum & Maksimum \\
\hline Glukoz (mg/dl) & $132 \pm 73$ & 72.00 & 479.00 \\
\hline Üre (mg/dl) & $106 \pm 34$ & 59 & 211.00 \\
\hline Kreatinin (mg/dl) & $8.5 \pm 2.8$ & 5.00 & 16.30 \\
\hline Ürik asit (mg/dl) & $6 \pm 1$ & 4.00 & 8.80 \\
\hline Sodyum (mmol/L) & $139 \pm 3.5$ & 132.00 & 148.00 \\
\hline Potasyum (mmol/L) & $4 \pm 0.7$ & 3.00 & 6.00 \\
\hline Parathormon (pg/ml) & $576 \pm 443$ & 80.00 & 1900.00 \\
\hline Kalsiyum (mg/dl) & $9.1 \pm 0.6$ & 7.90 & 10.30 \\
\hline Fosfor (mg/dl) & $5.1 \pm 1.2$ & 2.90 & 8.60 \\
\hline Kalsiyum $x$ fosfor $\left(\mathrm{mg}^{2} / \mathrm{dl}^{2}\right)$ & $46.7 \pm 11.7$ & 26.00 & 77.00 \\
\hline Albümin (g/dl) & $3.8 \pm 0.4$ & 2.70 & 4.50 \\
\hline Total kolesterol (mg/dl) & $182 \pm 45$ & 113.00 & 338.00 \\
\hline HDL-kolesterol (mg/dl) & $42 \pm 17$ & 20.00 & 90.00 \\
\hline LDL-kolesterol (mg/dl) & $108 \pm 35$ & 58.00 & 235.00 \\
\hline Trigliserid (mg/dl) & $166 \pm 97$ & 35.00 & 475.00 \\
\hline AST (U/L) & $17 \pm 7$ & 6.00 & 37.00 \\
\hline ALT (U/L) & $17 \pm 9$ & 5.00 & 39.00 \\
\hline $\operatorname{ALP}(\mathrm{U} / \mathrm{L})$ & $139 \pm 213$ & 48 & 1423 \\
\hline Hemoglobin (g/dl) & $10.7 \pm 1.5$ & 6.9 & 14.30 \\
\hline Hematokrit (\%) & $32.5 \pm 4.2$ & 21.40 & 42.70 \\
\hline Lökosit (/mm³) & $8321 \pm 2754$ & 3500 & 16800 \\
\hline Trombosit (x103) & $265 \pm 90$ & 40 & 432 \\
\hline $\operatorname{MCV}(f l)$ & $92 \pm 5$ & 83 & 107.00 \\
\hline Ferritin (ng/ml) & $385 \pm 335$ & 25 & 1650.00 \\
\hline
\end{tabular}

Tablo 3. Hastaların PET bulguları

\begin{tabular}{|c|c|c|c|}
\hline & Ort $\pm S D$ & Minimum & Maksimum \\
\hline Periton membran geçirgenliği & $0.68 \pm 0.11$ & 0.47 & 0.87 \\
\hline Total Kt/V & $2.44 \pm 0.67$ & 1.42 & 4.00 \\
\hline Diyalizat Kt/V & $1.78 \pm 0.50$ & 0.71 & 3.38 \\
\hline Renal Kt/V & $0.67 \pm 0.68$ & 0.00 & 2.59 \\
\hline Total üre klirensi & $86 \pm 21.4$ & 55.6 & 150.7 \\
\hline Diyalizat üre klirensi & $61.8 \pm 14.6$ & 35.3 & 99.7 \\
\hline Rezidüel renal üre klirensi & $23.9 \pm 24.5$ & 0.00 & 94.9 \\
\hline Total kreatinin klirensi & $76.7 \pm 27.3$ & 34.4 & 157.9 \\
\hline Diyalizat kreatinin klirensi & $45.3 \pm 13.4$ & 21.5 & 83.9 \\
\hline Rezidüel renal kreatinin klirensi & $31.1 \pm 30.9$ & 0.00 & 118.8 \\
\hline
\end{tabular}

(sırasıyla \%12.4 \pm 7.5 ve $\% 10.1 \pm 6.21 ; p=0.383$ ). Aspirin kullanan hastalar ile kullanmayanlar arasında AAD yüzdesi açısından istatiksel açıdan anlamlı bir farklılık yoktu (sırasıyla $\% 10.4 \pm 5.7$ ve $\% 10.8 \pm 6.8 ; p=0.903$ ).

\section{Tartışma}

SDBY'de mortalitenin en önemli nedeni KVH'dır. KVH patogenezinde de ED'nin çok önemli bir yer tuttuğu bilinmektedir $(1,2)$. Üremik hastalarda ED'ye neden olan birçok faktör tanımlanmışıı. Çalışmamızda PD hastalarında AAD yüzdesi olarak ifade edilen endotel fonksiyonları ile apelin arasında negatif bir korelasyon $(r=-0.334, p=0.03)$ saptandı. Literatürde PD hastalarında AAD yüzdesi ile apelin arasındaki ilişkiyi inceleyen bir çalışmaya rastlanmadı. Ancak Malyszko ve arkadaşlarının yaptığı iki ayrı çalışmada hemodiyaliz hastalarında apelinin endotelyal fonksiyonlarla bağlantılı biyokimyasal göstergelerle ilişkili olduğu bulunmuştur $(13,14)$. Apelin normalde endotel hücrelelerinde epitelyal nitrik oksit sentaz aracılığıyla cGMP düzeyini arttırarak vazodilatasyon ve kan basıncını düşürücü etki yapar. Ancak disfonksiyone endotel varlığında vazkonstrüksiyon yapar $(8,9)$. Sağıklı insanlarda yapılan bir çalışmada apelin infüzyonunun nitrik oksit bağımlı mekanizma ile arteriyel vazodilatasyon yaptığı gösterilmiştir (15). Başka bir çalışmada ise KY olan hastalara ekzojen apelin verilmesiyle hem periferik hem de koroner vazodilatasyon gözlenmiş̧ir (16). Çalışmamız her ne kadar kesitsel çalışma olarak planlanmış olsa da, AAD yüzdesi ile saptanan negatif ilişki, apelinin disfonksiyone endotel varlığında vazodilatasyon yapıcı etkisinin yansıması olarak kabul edilebilir.

Yaptığımız çalışmada $A A D$ yüzdesi ile $S K B$ ve $D K B$ arasında anlamlı bir negatif korelasyon mevcuttu. AAD yüzdesi hipertansif ve diyabetik grupta daha düşük bulundu. HT olan PD hastalarımızda AAD yüzdesi HT olmayanlara göre belirgin şekilde düşüktü. Zira böbrek yetmezliği olmayan popülasyonda yapılan bir çalışmada AAD yüzdesi ile SKB arasında ters bir ilişki saptanmıştır (17). Başka bir çalışmada ise 24-39 yaş arası genç hastalarda da AAD yüzdesi ile kan basıncı arasında negatif bir korelasyon gözlenmiştir (18). Ancak literatürde PD hastalarında direkt olarak AAD ile kan basıncı ilişkisine yönelik herhangi bir veri bulamadık.

Çalışmamızda AAD yüzdesi İKH olan grupla olmayan grup arasında anlamlı bir fark göstermedi. Bu olasılıkla bizim İKH hasta sayımızın oldukça düşük olmasından kaynaklanmaktaydı. AAD yüzdesi $K Y^{\prime} l i$ hastalarda $K Y^{\prime} l i$ olmayanlara göre belirgin şekilde düşüktü, ancak bu istatiksel açıdan anlamlı bir fark oluşturmadı. Bu durumun KY olan hasta sayısının sadece iki tane olmasına bağlı olabileceğini düşündük. Zira genel popülasyonda yapılan çalışmalarda ED varlığının IKH için 
önemli bir öngörücü olarak bulunmuştur (19). AAD yüzdesi beklendiği üzere diyabetik olmayanlarda diyabetiklere göre daha yüksekti. Çalışmamızda hiperlipidemisi olan hastalar ile olmayanlar arasında AAD yüzdesi açısından anlamlı bir fark yoktu. Ancak trigliserid ve VLDL düzeyleri ile $A A D$ yüzdesi arasında pozitif bir ilişki mevcuttu. Bae ve arkadaşları yaptığı çalışmada postprandiyal hipertrigliserideminin endotelyal fonksiyonlarda bozulma yaptığını ileri sürmüştür ve trigliserid ile AAD yüzdesi arasında negatif bir korelasyon saptamışırı (20). Bulgularımızdaki bu farklılıklar PD hastalarındaki lipid metabolizmasının normal popülasyondan farkılık göstermesine bağlı olabilir.

Bir çalışmada PD hastalarında AAD yüzdesi ile rezidüel renal fonksiyonlar arasında anlamlı bir ilişki saptanmıştır (21). Ancak bizim çalışmamızda AAD yüzdesi ile PET'deki diyaliz yeterlilik parametreleri ve rezidüel renal fonksiyonlar arasında herhangi bir ilişki yoktu. Bu durum bizim hasta sayımızın daha düşük olmasına bağlı olabilir (sırasıyla 72 hastaya 42 hasta).

$A A D$ yüzdesi renin anjiyotensin aldosteron sistemi (RAAS) blokeri kullanan hastalarda kullanmayanlara göre belirgin olarak daha düşük bulundu (sırasıyla \%7.2 24.8 ve $\% 11.9 \pm 6.7$; $\mathrm{p}=0.05$ ). Literatürde böbrek yetmezliği olmayan hipertansif hastalarda ACE-i ve ARB'lerin endotel fonksiyonlarını koruduğuna dair yayınlar mevcuttur $(22,23)$. Han ve arkadaşlarının yaptığı çalışmada ise PD hastalarına 6 ay valsartan verilmesinden sonra $A A D$ yüzdesinde düzelme görmüşlerdir (24). Bizim hastalarımızda RAAS blokeri kullananlardaki bu düşük $A A D$ yüzdesi muhtemelen hasta popülasyonundaki farklııklara ve yukarıdaki çalışmalarda RAAS blokerlerinin AAD yüzdesine etkisinin ileri dönük olarak incelenmiş olmasına bağlı olabilir. Zira bizim çalışmada genel olarak HT nedeniyle RAAS blokeri başlanmış hastalar; yani baştan itibaren ED daha belirgin hastalar ile RAAS blokeri kullanmayan hastalar karşılaştııılmıştır.

Statin kullanan hastalarımız ile kullanmayanlar arasında AAD yüzdesi açısından anlamlı bir fark yoktu (sırasıyla $\% 12.4 \pm 7.5$ ve $\% 10.1 \pm 6.21 ; p=0.383$ ). Han ve arkadaşlarının PD hastalarında yaptığı çalışmada valsartan tedavisine eklenen statinin sadece ARB tedavisine göre endotel fonksiyonlarını daha iyi koruduğu gözlenmiştir (24). İeri dönük yapılan bir çalışmada stabil koroner arter hastalığı olanlarda agresif statin tedavisine geçen hastalarda endotel fonksiyonlarının daha iyi korunduğu bulunmuştur (25). Başka bir çalışmada ise atorvastatinin tip 2 DM'lu hastalarda endotel fonksiyonlarında iyileşme yaptığı saptanmıştır (26). Hasta popülasyonundaki farklılıklarımız ve çalışma dizaynımızın farklı olması nedeniyle bizim çalışmamızda farklı sonuçlar elde edilmiştir.
Aspirin kullanan hastalar ile kullanmayanlar arasında AAD yüzdesi açısından anlamlı bir fark yoktu (sırasıyla \%10.4 5 5.7 ve $\% 10.8 \pm 6.8 ; p=0.903)$. Gunes ve arkadaşlarııın yaptığı çalışmada koroner yavaş akımı olan hastalar arasında sadece aspirin verilen hastalarda $A A D$ yüzdesine herhangi bir düzelme gözlenmemiştir (27). Bu veri bizim sonuçlarla uyumludur.

\section{Sonuç}

ED, PD hastalarında HT ve lipid profili ile yakın ilişkilidir. Apelin PD hastalarında ED açısından bir belirteç olabilir. Apelinerjik sistemin endotel üzerine etkileri düşünüldüğünde ED tedavisi açısından da yeni bir alternatif olarak değerlendirilmesi ve bu yönde ileri araştırmaların yapılması faydalı olacaktır.

\section{Kaynaklar}

1. Miller LM, Sood MM, Sood AR, et al. Cardiovascular disease in end-stage renal disease: the challenge of assessing and managing cardiac disease in dialysis patients. Int Urol Nephrol 2010;42:1007-14.

2. Tatematsu S, Wakino S, Kanda T, et al. Role of nitric oxideproducing and-degrading pathways in coronary endothelial dysfunction in chronic kidney disease. J Am Soc Nephrol 2007; 18:741-9.

3. O'Dowd BF, Heiber M, Chan A, et al. A human gene that shows identity with the gene encoding the angiotensin receptor is located on chromosome 11. Gene 1993;136:355-60.

4. Tatemoto $K$, Hosoya $M$, Habata $Y$, et al. Isolation and characterization of a novel endogenous peptide ligand for the human APJ receptor. Biochem Biophys Res Commun 1998:251:471-6.

5. Ladeiras-Lopes R, Ferreira-Martins J, Leite-Moreira AF. The apelinergic system: the role played in human physiology and pathology and potential therapeutic applications. Arq Bras Cardiol 2008:90:343-9.

6. Japp AG, Newby DE. The apelin-APJ system in heart failure pathophysiologic relevance and therapeutic potential. Biochem Pharmacol 2008;75:1882-92.

7. Falcao-Pires I, Leite-Moreira AF. Apelin: a novel neurohumoral modulator of the cardiovascular system: pathophysiologic importance and potential use as a therapeutic target. Rev Port Cardiol 2005;24:1263-76.

8. Tatemoto K, Takayama K, Zou MX, et al. The novel peptide apelin lowers blood pressure via a nitric oxide-dependent mechanism. Regul Pept 2001;99:87-92.

9. Katugampola SD, Maguire JJ, Matthewson SR, Davenport AP. [(125)I]-(Pyr(1))Apelin-13 is a novel radioligand for localizing the APJ orphan receptor in human and rat tissues with evidence for a vasoconstrictor role in man. Br J Pharmacol 2001:132:1255-60.

10. Szakodi I, Tavi P, Foldes G, et al. Apelin, the novel endogenous ligand of the orphan receptor APJ, regulates cardiac contractility. Circ Res 2002;91:434-40.

11. Taheri S, Murphy K, Cohen M, et al. The effects of centrally administered apelin-13 on food intake, water intake and pituitary hormone release in rats. Biochem Biophys Res Commun 2002;291:1208-12.

12. Malyszko J, Malyszko JS, Kozminski P, Mysliwiec M. Apelin and cardiac function in hemodialyzed patients: possible relations? Am J Nephrol 2006;26:121-6. 
13. Malyszko J, Malyszko JS, Pawlak K, Mysliwiec M. Visfatin and apelin, new adipocytokines, and their relation to endothelial function in patients with chronic renal failure. Adv Med Sci 2008;53:32-6.

14. Malyszko J, Malyszko JS, Pawlak K,Wolczynski S, Mysliwiec M. Apelin, a novel adipocytokine, in relation to endothelial function and inflammation in kidney allograft recipients. Transplant Proc 2008;40:3466-9.

15. Japp Ag, Cruden NL, Amer DA, et al. Vascular effects of apelin in vivo in man. Am Coll Cardiol 2008;52:908-13.

16. Japp Ag, Cruden NL, Barnes G, et al. Acute cardiovascular effects of apelin in humans: potential role in patients with chronic heart failure. Circulation 2010;121:1818-27.

17. Benjamin EJ, Larson MG, Keyes MJ, et al. Clinical correlates and heritability of flow-mediated dilation in the community: the Framingham Heart Study. Circulation 2004;109:613-9.

18. Juonala M, Viikari JS, Laitinen $T$, et al. Interrelations between brachial endothelial function and carotid intima-media thickness in young adults: the cardiovascular risk in young Finns study. Circulation 2004;110:2918-23.

19. Schroeder S, Enderle MD, Ossen $R$, et al. Noninvasive determination of endothelium-mediated vasodilation as a screening test for coronary artery disease: pilot study to assess the predictive value in comparison with angina pectoris, exercise electrocardiography, and myocardial perfusion imaging. Am Heart J 1999;138:731-9.

20. Bae JH, Bassenge $E$, Kim KB, et al. Postprandial hypertriglyceridemia impairs endothelial function by enhanced oxidant stres. Atherosclerosis. 2001;155:517-23.
21. Han SH, Lee SC, Kang EW, et al. Reduced residual renal function is associated with endothelial dysfunction in patients receiving peritoneal dialysis. Perit Dial Int 2012;32:149-58.

22. Yavuz D, Koc, M, Toprak A, et al. "Effects of ACE inhibition and AT1-receptor antagonism on endothelial function and insulin sensitivity in essential hypertensive patients," J Renin Angiotensin Aldosterone Syst 2003;4:197-203.

23. Koh KK, Han SH, Chung WJ, et al. "Comparison of effects of Losartan, Irbesartan, and Candesartan on flowmediated brachial artery dilation and on inflammatory andn thrombolytic markers in patients with systemic hypertension," Am J Cardiol 2004;93:1432-5, A10.

24. Han SH, Kang EW, Yoon SJ, et al. Combined vascular effects of HMG-CoA reductase inhibitor and angiotensin receptor blocker in non-diabetic patients undergoing peritoneal dialysis. Nephrol Dial Transplant 2011;26:3722-8.

25. Hoshiga M, Arishiro K, Nakakoji T, et al. Switching to aggressive statin improves vascular endothelial function in patients with stable coronary artery disease. J Atheroscler Thromb 2010;17:705-11.

26. Amudha K, Choy AM, Mustafa MR, Lang CC. Short-term effect of atorvastatin on endothelial function in healthy offspring of parents with type 2 diabetes mellitus. Cardiovasc Ther 2008;26:253-61.

27. Gunes Y, Gumrukcuoglu HA, Akdag S, Simsek H, Sahin M, Tuncer M. Vascular endothelial function in patients with coronary slow flow and the effects of nebivolol. Arq Bras Cardiol 2011;97:275-80. 